\title{
A PANDEMIA DA COVID-19 COMO VITRINE DA PRECARIZAÇÃO DO TRABALHO DOCENTE E DA EDUCAÇÃO: DESAFIOS PARA O ENSINO EM UMA DEMOCRACIA FRAGILIZADA
}

\author{
Fernanda Fochi Nogueira Insfran ${ }^{\mathrm{i}}$ \\ Paulo Afonso do Prado ${ }^{\text {ii }}$ \\ Samela Estéfany Francisco Faria ${ }^{\text {iii }}$ \\ Thalles Azevedo Ladeira ${ }^{\text {iv }}$ \\ Tiago Afonso Sentinelli ${ }^{\mathrm{v}}$ \\ Waldyr Barcellos Junior ${ }^{\mathrm{vi}}$
}

\begin{abstract}
Resumo: Motivados por uma pesquisa nacional em andamento sobre educação e pandemia, objetivamos debater o processo antidemocrático construído na educação pública, que responde por seu estrangulamento. Em meio à pandemia da Covid-19, vozes docentes rompem as mordaças para denunciar as impossibilidades de uma educação democráticaapós a intensificação dos desmontes, das ameaças de perda de autonomia e da precarização das condições de trabalho/ vida com a imposição intencional, atabalhoada e excludente do ensino remoto. Assim, reflexões teóricas e dados sobre a crise sanitária e o desigual acesso à tecnologia e direitos básicosapontam para a necessidade de uma democracia participativa mais forte, com debate e elaboração coletiva de políticas públicas que garantam saúde e educação para todos.
\end{abstract}

Palavras-chave: Democracia; Comunidade escolar; Ensino remoto; Autoritarismo; Pandemia.

\section{THE COVID-19 PANDEMIC AS A SHOWCASE FOR THE PRECARIOUS TEACHING WORK AND EDUCATION: CHALLENGES FOR TEACHING IN A FRAGILIZED DEMOCRACY}

\begin{abstract}
Motivated by an ongoing brazilianresearch about education and the pandemic, we aim to debate the anti-democratic process built in the public education, which it is responsible for its strangulation. Amidst of the Covid-19 pandemic, teacher's voices break the gags to denounce the impossibilities of a democratic education, after the intensification of the dismantling, the threats of loss of autonomy and the precariousness of the work/ life conditions after the intentional, confused and excluding imposition of remote education. Thus, theoretical reflections and data on the health crisis and the unequal access to technology and basic rights, point to the need for a stronger participative democracy, with debate and collective elaboration of public policies that guarantee health and education for all.
\end{abstract}

Keywords: Democracy; School community; Remote teaching; Authoritarianism; Pandemic. 


\section{Introdução}

Não acredito mais na democracia, partidos políticos, mídias, etc. Estamos completamente abandonados à própria sorte. ${ }^{\text {vii }}$

A fala que está na epígrafe acima foi uma das preocupações que fomentou as discussões que faremos neste artigo. Encontrá-la, entre as milhares de respostas dadas pelos participantes de uma pesquisa online sobre educação na pandemia, nos acendeu o alerta de que nossa jovem e frágil democraciaestaria desacreditada até mesmo entre aqueles que deveriam ensinar aos pequenos a importância deste regime político que zela por igualdade, liberdade e representatividade. É claro que diversas variáveis influenciam/ influenciaram o que as pessoas entendem (ou entendiam) pela palavra democracia: origem; nacionalidade; momento histórico; escolaridade; interesses; subjetividades; etc. (MARKOFF, 2013). Mas nos instiga entender: por que estaríamos vivendo hoje essa descrença nas instituições democráticas, verbalizada por uma parcela da população no mundo todo, que inclusive tem apoiado movimentos antidemocráticos e o retorno de regimes autoritários de poder (BOULOS, 2016; FRIGOTTO, 2019)? E como isso reflete nas relações escolares, nas crenças e atitudes da comunidade escolar?

Além disso, as vivências compartilhadas pelos/as professores/as participantes desta pesquisa, que está sendo realizada pelo Núcleo de Estudos Interseccionais em Psicologia e Educação (NEIPE/UFF), se somam a muitas das nossas vivências como docentese motiva-nos a querer refletir sobre democracia e autoritarismo nas tomadas de decisões/ construção das políticas educacionais. Não é nossa intenção apresentar resultados da pesquisa online realizada durante a pandemia com 1910 professores de todo o país, pois os resultados da mesma ainda estão em análise. Objetivamos aqui apresentar reflexões teóricas amparadas em autores das ciências humanas e em dois importantes marcos legais da construção democrática das políticas públicas em educação: a atual Constituição (BRASIL, 1988) e a Lei de Diretrizes e Bases da Educação (BRASIL, 1996), que juntas garantem à comunidade escolar descentralização, participação e autonomia nas decisões educacionais (NOGUEIRA, 2006).

Partindo de falas como esta - "na escola em que leciono não se tem o devido respeito pela democracia e os colegas docentes são indiferentes aos desmandos das equipes gestoras" "viii -, nos surge como hipótese que a burocratização dos processos democráticos de participação nas decisões escolares e a consequente tradição autoritária (PATTO, 2009) presente nas relações (fortemente hierarquizadas) são grandes entraves à efetiva democracia 
na educação pública. É claro que estes não são os únicos problemas que enfrentamos, já que não podemos considerar nossa educação democrática com toda a exclusão existente, intensificada nestes tempos de pandemia.

Diversos autores apontam as dificuldades que devem ser superadas/ erradicadas para que políticas públicas democráticas sejam implementadas: a existência e manutenção das hierarquias de poder (PATTO, 2009; SOUZA, 2011), bem como o pouco diálogo com o "chão de escola" sobre a implementação de modelos e políticas educacionais; esta primeira dificuldade implica diretamente na frustração e desânimo observado entre muitos profissionais de educação, que se sentem desconsiderados enquanto profissionais e pessoas (ASBAHR, 2011); pouca conexão entre as políticas educacionais implementadas e as necessidades reais das comunidades escolares (SOUZA, 2011); concepções preconceituosas arraigadas social e culturalmente em toda a comunidade escolar, que creditam aos alunos pobres e suas famílias toda a sorte de fracassos e dificuldades escolares (PATTO, 2009, 2015); tais concepções são, em parte, fruto de uma política de formação de professores tecnicista que contribui para a alienação do trabalho pedagógico (ASBAHR, 2011; INSFRAN, 2017); e a quase inexistência de espaços/ tempos para debates e construção dialógica e democrática das políticas educacionais que precisam ser implementadas (SOUZA, 2011; INSFRAN, MUNIZ, ARAUJO, 2019).

De fato, nos parece curioso que se creia que a educação brasileira seja de fato democráticaquando ainda não há acesso equitativo ao conhecimento produzido;ou a implementação de uma relação dialógica entre comunidades, instituições de ensino e aqueles que operam o sistema educacional em nosso país. Em tempos de pandemia, as desigualdades estão afloradas e impera o autoritarismo na tomada de decisões, conforme vemos acontecer com a precária, atabalhoada e excludente implantação do ensino remoto em milhares de instituições de ensino.

Assim, se justifica pensar na pandemia como um acontecimento que descortina e expõe as tensões sociais e deixa nítida a luta de classe, que está em cena sem que muitas pessoas tenham consciência da sua existência.

As relações de classe sofrem interferências de padrões de tratamento que são antes estamentais e que reproduzem o passado no presente, a tal ponto que o horizonte cultural inerente à consciência conservadora de nossos dias, em seu mandonismo, exclusivismo e particularismo agreste, lembram mais a simetria "colonizador" versus "colonizado" que a "empresário capitalista" versus "assalariado". Isso evidencia o quanto a ordem civil ainda não atingiu mesmo grupos incorporados ao mercado capitalista de trabalho e ao sistema de relações de classes, demonstrando que a distância social entre as classes 
nem sempre é uma mera questão quantitativa. Aquele padrão compatibiliza a coexistência da tolerância e até da cordialidade com um profundo desdém elitista por quem não possua a mesma condição social. O que faz com que aquilo que parece "democrático", na superfície, seja de fato "autoritário" e "autocrático", em sua essência. Esse patamar psicossocial das relações humanas é a nossa herança mais duradoura (e, ao mesmo tempo, mais negativa) do passado colonial e do mundo escravista (FERNANDES, 1976, p.21, grifos do original).

Florestan Fernandes (1976) nos dá subsídios para refletir sobre o modo como a educação presencial nos foi arrancada diante do acontecimento da pandemia, pois fica evidente, da forma como foi realizada, o caráter da dialética pensada pelo autor, onde um modelo supostamente acessível daria conta de agregar os diferentes. Mas se é fato que a educação deve ser universal, seu formato digital mostra ainda mais o seu lado segregador. Lembremos que para Florestan Fernandes, adepto ao marxismo de modo irreparável, a educação seria o caminho para a construção de uma sociedade dona de si mesma, pois é emancipadora e não poderia mais servir como símbolo de privilégios e de poder que mantém a todos em uma realidade forjada para a manutenção das desigualdades sociais.

Isso nos leva a pensar em outro elemento dessa conjuntura: a relação de forçasque mais uma vez traz o raciocínio sobre a relação colonial vivida dentro da estrutura educacional brasileira. Esta relação de forças, segundo Souza (2016), faz emergir as características da estrutura de nossa educação em comparação com a realidade encontrada no cotidiano dos indivíduos e das instituições que constroem o sistema que se pretende universal, que trata de modo igual todos aqueles que são desiguais social e historicamente.

\section{Democracia burocratizada: entraves à real descentralização, autonomia e participação na educação}

Meu maior questionamento hoje em dia é: como ajudar na construção da
autonomia de um indivíduo se constantemente está sendo tirada a minha
liberdade de criação, se tenho que seguir, cada vez mais, modelos
padronizados e definidos de forma hierárquica onde não existe minha
participação e contribuição?

Objetivando entender a educação a partir da ideia de democracia, podemos buscar na história o modelo escolhido pelos grupos hegemônicos, como ideal de prática democrática, que seria o modelo ateniense. E se faz importante ressaltar que escolher a sociedade grega como referência política é uma atitude praticada pelos grupos hegemônicos, pois a educação é um ato político e seu fruto, o conhecimento, que pode transformar a realidade para melhor, é uma posse restrita àquelesque historicamente tiveram o privilégio de pagar por um bom tutor. 
Pessanha et al (1991) nos fazem lembrar de Sócrates, que ao tentar difundir conhecimento e estimular a prática da maiêutica ${ }^{\mathrm{x}}$, foi julgado e condenado à morte por ser acusado pelas elites sofistas de subverter a juventude. Assim, preferiu aceitar a morte do que negar que seu intento era libertar a mente de outrem das amarras da condicionalidade dos projetos aristocráticos, sempre desejosos pela perpetuação de sua posição mandatária e opressora.

Se hoje a cidadania é constituída por um conjunto de direitos civis, políticos e sociais, os atenienses na antiguidade pensaram que a cidadania seria exercida e/ou constituída pela prática da oratória acerca da "coisa pública", com a finalidade de tornar a realidade coletiva um espaço de qualidade de vida. Exprimir opiniões, refletir sobre a realidade e debaterseria a construção desta hermenêutica democrática. A oratória,por sua vez, seria exercitada através de práticas culturais que subjazem por natureza à ideia de educação, de transmissão de valores, práticas morais constituintes de uma ética política. Assim, seria possível compreender a educação como uma realidade inseparável da prática cidadã e formadora da cultura de um povo (FERNANDES, 2013).

No Brasil, temos uma Constituição (BRASIL, 1988) em vigência que se consagrou como cidadã, por ter em seu bojo não só o fortalecimento da democracia, mas a vanguarda na concessão de direitos, ampliação de garantias, pelo modo como foi construída, supondo o princípio do exercício de cidadania nos moldes atenienses, ao trazer a população para o debate junto aos deputados constituintes, para a coleta dos anseios populares e construção do conjunto de textos que deram corpo a esta lei.

Foi a elaboração deste texto que permitiu, dentre outras coisas, construir o modelo de educação planejado para este novo momento social, de redemocratização, processo iniciado em 1979 (após a anistia dos exilados políticos, que perdura até 1985). Dentre as novas diretrizes da educação brasileira, podemos citar a maior diretriz educacional brasileira, a lei n9.394/96, a Lei de Diretrizes e Bases da Educação Brasileira (BRASIL, 1996), que por sua vez trouxe os Parâmetros Curriculares Nacionais - PCN's (BRASIL, 1997), com a ideia da transversalidade com vias ao trabalho pedagógico interdisciplinar; a Política Nacional de Educação Especial na Perspectiva da Educação Inclusiva (BRASIL, 2008); e mais recentemente, a Base Nacional Comum Curricular - BNCC (BRASIL, 2019), só para citar algumas políticas públicas que têm por interesse melhorar os processos de ensinoaprendizagem, objetivando a ampliação do acesso à educação e à diversificação de suas modalidades, para assim dar conta das diferenças sociais existentes na macro estrutura educacional do Brasil. 
Contudo, temos dentro da democracia um elemento de ambiguidade: a nossa Constituição (BRASIL, 1988) que se propôs a tornar cidadãos o maior número de brasileiros, traz em si um sistema de freios e contrapesos ${ }^{\mathrm{xi}}$. Esse sistema, criado na intenção de tornar público o debate acerca das questões administrativas do governo brasileiro, torna morosa a adoção de medidas que poderiam, no caso da educação, amenizar as distorções entre as legislações e a realidade educacional, em função do alto grau de trâmites burocráticos que engessam a aplicação das ações. Essa burocracia dificulta e impede, muitas vezes, que os participantes do sistema educativo compreendam o funcionamento do mesmo, a começar pelo processo de formação dos professores, passando pela manutenção das instituições de ensino e (não) chegando aos lares dos brasileiros. Essa constatação é um argumento que se estabelece como crítica em direção à burocracia de nosso Estado, que transformou o sistema de freios e contrapesos em uma prática de procrastinação, adiamento e depósito de inúmeros bons projetos ainda hoje não debatidos pelo Congresso Nacional (ABRUCIO, LOUREIRO, 2018; WEFFORT, 1998).

Pensar a educação dentro de um contexto democrático também nos leva a pensar a descentralização, a participação e a autonomia dos atores sociais e das instituições educativas, ações exigidas do Estado em favor do fortalecimento da educação democrática (NOGUEIRA, 2006). Entendemos que "é no bojo da redemocratização do Estado, da descentralização do poder para os Municípios e Estados, que a Educação passa a ter autonomia para planejar, implementar e gerir suas políticas educacionais" (CFP, 2019, p.28).

Comecemos, assim, o nosso pensar pelo princípio da descentralização, que dentro de um Estado neoliberal pode ser apenas uma forma nova de manter antigas estruturas organizacionais, ficcionando a abertura para a ampla participação. Foram criados os grêmios estudantis, grupos de pais, conselhos fiscais, conselhos escolares, etc. para serem ocupados pelos grupos que constituem a comunidade escolar. Entretanto, julgamos que a sua formação é viciosa por ser orientada por aqueles que gerem os micro sistemas educacionais, isto é, os gestores das escolas, que para atender a interesses já estabelecidos nas ações institucionais, interferem na escolha e condução dos indivíduos às funções que compõem esses órgãos escolares.

Assim, percebemos que estas práticas autoritárias e pouco transparentes são comuns no cotidiano das instituições educacionais, inviabilizando uma real descentralização, participação e, principalmente, autonomia da comunidade escolar. Com essa realidade instalada, é produzida a falsa sensação de que se faz parte da estrutura simplesmente pela concessão do direito de participação, mas que na prática não reconstrói as estruturas porque 
não rotaciona as funções entre os membros da comunidade escolar. Estes são intencionalmente levados a não se acreditarem capazes, acabam manifestando desinteresse em integrar essa base potencialmente transformadora que conduziria a escola, a comunidade e o sistema educacional para o patamar emancipador que constitui a sua essência (NOGUEIRA, 2006).

E é a autonomia que representa uma outra parcela importante da discussão sobre a democratização da educação, pois nela seriam depositadas as credenciais de construção dos moldes estruturais e pedagógicos que numa perspectiva local poderiam suscitar maior participação popular nos assuntos da escola, do fazer pedagógico e da formação de um vínculo identitário entre comunidade e escolas (NOGUEIRA, 2006).

Porém, o que se vê na prática são instituições afundadas em demandas burocráticas, que cobram dos gestores escolares mais saberes administrativos do que pedagógicos (ASBAHR, 2011). A autonomia, muitas vezes, acaba se resumindo à elaboração do Projeto Político Pedagógico (PPP) que, segundo a LDB (BRASIL, 1996), deveria ser construído coletivamente em cada instituição educacional pelos docentes, demais profissionais de educação, comunidade escolar e local. Asbahr (2011) enfatiza que cada projeto deve conter "um posicionamento político, um compromisso com algo e um direcionamento ideológico" (ASBAHR, 2011, p.78). Daí este documento ser, por excelência, aquele que evocaria a democracia escolar, a autonomia e a participação nos processos educativos. Entretanto, essa ideia de que a escola possui autonomia para elaborar sua diretriz pedagógica é tão falaciosaque nem mesmo professores sentem-se motivados a colaborar com a sua construção ou reconstrução, pois sabem que no final de todo o trabalhopublicam-se as resoluções em Diário Oficial que tratarão do calendário operacional escolar, apontando quais serão as ações a serem desenvolvidas no interior das escolas ao longo do ano letivo (ASBAHR, 2011).

Desse modo, professores e equipespassam a executar tarefas sem questionamentos, apenas para cumprir uma espécie de "check list" do que está na letra fria da lei, inclusive no que diz respeito à democratização, participação e autonomia, para isentarem-se de responsabilidades. Atitude presente não apenas em circunstâncias consideradas "normais" (que nunca as são), mas ainda mais enraizadas agora, durante o isolamento social. A precariedade do trabalho docente, com sua tão naturalizada vulnerabilidade financeira, faz suas forças se esvaírem frente à quebra do sistema educacional, que através da educação remotavigia o trabalho dos professores sob a égide do cumprimento da carga horária letiva, que condiciona pagamentos, avanços salariais e até mesmo férias. Como exemplo, citamos mais uma das respostas recebidas em nossa pesquisa online (já supracitada). Ao ser 
perguntado sobre sentir-se pressionado a realizar alguma atividade da qual discordasse, um profissional de educação respondeu: "Sim. frases como 'faça isso pois assim garante o seu ponto' foram ouvidas desde o começo do ano”. E antes de encerrar a sua participação, fez outra declaração que corrobora nossa fundamentação: "Não recebo salário nem transporte, nada desde que comecei. Dizem que o Estado de SP tem como padrão demorar 3 a 4 meses para pagar", xii

Seguimos assim, portanto, antes e durante a pandemia, um modus operandi nas relações entre gestores e comunidade escolar que não permite a descentralização das decisões, dar mais autonomia e gerar envolvimento da comunidade escolar.

\section{Os movimentos antidemocráticos e a tentativa de naturalização do autoritarismo na sociedade e na educação}

Ampliação do autoritarismo e da perseguição ideológica tendo em vista a negação do governo em relação à ciência e à pluralidade de ideias e concepções pedagógicas. ${ }^{\text {xii }}$

A epígrafe acima expressa a preocupação de um professor participante da nossa pesquisa com relação ao futuro incerto que nos espera pós pandemia. Pensar que existe o perigo de uma ampliação do autoritarismoé afirmar a existência dele entre nós. Conforme vimos no tópico anterior, está claro para muitos autores que existem diversos entraves à construção democrática das políticas e decisões educacionais. Porém, a fala acima expõe uma preocupação extra, que decorre da onda conservadora que emergiu no Brasil e no mundo nos últimos anos. Alguns autores apontam que no caso brasileiroesta onda se estabelece com mais força e legitimidade a partir das manifestações/ jornadas de junho de 2013 (BOULOS, 2016; DEMIER, 2016; FRIGOTTO, 2019), momento em que manifestações antidemocráticas e fascistas passaram a reivindicar o retorno da ditadura militar, o fechamento do Congresso Nacional e do Supremo Tribunal Federal.

A eclosão de manifestações contra o regime democrático vigente, expressada por parte da população, nos traz uma reflexão importante: historicamente os aspectos que caracterizam uma sociedade como democrática baseiam-se no ponto de vista daqueles que dominam e gozam dos privilégios sociais. É sobre essa égide que podemos citar, por exemplo, a noção de democracia que se tinha no século XVIII, com a população negra sendo escravizada e as mulheres sem qualquer direito a participação social (MARKOFF, 2013). 
A democracia parece ser intrinsecamente dinâmica, porque cria movimentos sociais encorajados pela frustração com o caráter pouco democrático da prática das instituições, incluindo-se aí os limites de inclusão e exclusão; porque seus vários postulados são, com frequência, contraditórios, possibilitando a diversos movimentos reivindicarem a bandeira democrática; porque os detentores do poder consideram útil afirmar que os arranjos políticos que os sustentam no comando são "democráticos", por menos equitativos e mais opressivos que possam ser; e porque movimentos antidemocráticos são criados juntamente com os movimentos em defesa de perspectivas democráticas alternativas. Não há razão para acreditar que a noção de democracia a prevalecer daqui a dois séculos será a mesma hoje vigente, assim como nosso entendimento atual de democracia não é o mesmo de quando as revoluções sociais criaram novas instituições há pouco mais de dois séculos (MARKOFF, 2013, p.28).

É nesse contexto que podemos citar o exemplo de movimentos antidemocráticos ao redor do mundo, que historicamente vêm tentando definir o que é democracia, pautados em seus próprios privilégios de classe, como é o caso do nazismo introduzido na Alemanha, do stalinismo na Rússia e do fascismo na Itália. Embora hoje se tenha acordo que foram regimes absolutamente totalitários, na época (início do século XX) eram legitimados pela sociedade e pela ciência - importante ressaltar que as teorias racistas do século XIX, baseadas no método científico positivista e eugenista, fortaleceram a tese de que a raça ariana era superior às demais (PATTO, 2015).

Assim, falando especificamente do Brasil e da onda conservadora que nos assola desde 2013, percebemos um retorno dessas concepções preconceituosas, racistas, antidemocráticas - hoje no cerne do governo federal - que se valem de um discurso nacionalista, moralista e desenvolvimentista/ neoliberal para legitimar perseguições e ameaças a grupos minoritários e extirpar direitos duramente conquistados (DEMIER, 2016).

Retornando à fala que mobilizou toda a discussão deste tópico, temos vivido, nestes últimos anos, enquanto docentes, o temor das perseguições e censuras mobilizadas pela extrema direita e pelos simpatizantes do movimento "Escola sem partido" (ESP) contra a chamada "doutrinação ideológica" - conceito cunhado pelos grupos conservadores que entendem o trabalho docente como instrumento de aparelhamento ideológico partidário (FRIGOTTO, 2019). A partir dessa crença, o movimento ESP tem tido expressiva adesão de grupos religiosos fundamentalistas, grupos políticos conservadores e de uma parcela da população.

Projetos educacionais promotores de uma educação crítica, reflexiva, de respeito à diversidade e à pluralidade de ideias e identidades - portanto emancipadora - têm sido condenados e perseguidos pelos apoiadores do ESP por serem considerados "doutrinação 
ideológica de esquerda" ou "doutrinação marxista" ou mesmo "ideologia de gênero" - estes têm sido os termos empregados pelo movimento ESP e similares (FRIGOTTO, 2019; LINARES, BEZERRA, 2019).

Isso faz com que o "Escola Sem Partido" seja visto como um movimento salvacionista da família e, ao passo em que consegue convencer a população dessa falácia, se fortalece no sentido de impor uma realidade de controle e vigilância no trabalho dos professores, sendo esta mais uma face da precarização. Apesar de ainda não ter sido aprovado nacionalmente - o projeto tramitou pelo Congresso Nacional por 4 anos e foi arquivado no final de 2018 (NOBRE, 2018) - algumas câmaras municipais aderiram ao que é conhecido entre os professores e os críticos ao ESP como "Lei da Mordaça” e que já vinha sendo gestado pelos seus idealizadores desde 2004 (PENNA, 2019).

Assim, os professores brasileiros, além de lidarem com todas as dificuldades cotidianas da educação pública em processo de desmonte (precárias condições de trabalho, saúde e existência), precisam se defrontar com ameaças de punição e criminalização de suas atividades docentes perpetradas pelos apoiadores do ESP. A pesquisa de doutorado de Felicio (2019) apresentou dezenas de casos de perseguição/ censura e o consequente adoecimento de professores, pois mesmo sem a aprovação do ESP como lei nacionala disseminação das suas ideias legitimou atitudes policialescas nos espaços escolares por parte de algumas famílias, promovendo um sentimento de coação e intimidação dos docentes, enfraquecendo a democracia e a garantia da autonomia destes.

Abaixo trazemos alguns fragmentos do texto de Ramos (2019) que evidenciam os objetivos do ESP com a mordaça que buscou impor aos docentes das escolas públicas:

Trata-se de tentar imprimir ao currículo escolar sua ideologia a qual, enunciada como neutra é, na verdade, totalmente comprometida com a classe dominante, pois impede que os interesses dos dominados sejam abordados na escola. [...] Se o conhecimento não é político em si, sem dúvidas o são as relações que o produzem e que dele fazem uso, seja na educação, seja na produção. Justamente por isto, sua distribuição tem sido tanto desigual quanto controlada. E é este controle que pretende o Escola sem Partido. Daí seu caráter antidemocrático e autoritário. [...] A desigualdade na distribuição do conhecimento que interessa à classe dominante e dirigente explica, então, porque neste país se continua tendo escolas pobres e para pobres. Explica, ainda, porque o Escola sem Partido quer controlar particularmente as políticas curriculares e a prática pedagógica da escola pública. Para eles, certamente, o professor que vem dos segmentos populares ou os "intelectuais de esquerda" que atuam nessas escolas são ameaçadores. Daí controlá-los, persegui-los e criminalizá-los (RAMOS, 2019, p.81-82). 
Oantidemocraticismonacional também se manifesta com o advento de discursos que propagam a ideia de que as escolas brasileiras não disciplinam seus alunos, partindo de um pressuposto que modela o objetivo da educação como o de recorrer a práticas de adequação e disciplinamento de sujeitos a um formato visto como o padrão aceitável. É nesse sentido que vários estados têm inserido nas suas redes o modelo de escolas cívico-militares, sob a alegação de com isso promover melhorias no processo de ensino-aprendizagem nas escolas públicas (BRASIL, 2017), ainda que para isso tenham que se utilizar de monitoramento, acompanhamento e ordenamento militar dentro das escolas, junto a discentes e docentes. A nós, no entanto, tal ato legitima ainda mais a busca por controle de sujeitos e subjetividades, além do ataque à educação e igualmente aos processos democráticos que são instituídos por lei dentro das escolas (BRASIL, 1996).

Este encantamento - observado na sociedade e também entre docentes - com a militarização escolar se sustenta em um viés de que com este processo, portanto, haverá diminuição da violência na escola e aumento no desempenho educacional (PICARELLI, 2019). Porém, dados do ENEM de 2017 evidenciam que os Institutos Federais Tecnológicos têm média superior aos Colégios Militares (SALDAÑ et al., 2019), supondo que os problemas das escolas se encontram concentrados no índice de avaliação escolar.

A militarização das escolas é apenas mais um exemplo de processos antidemocráticos existentes, cabendo citar ainda os atos de manifestações que pedem intervenção militar no Brasil (TEÓFILO, 2020), o que nos mostra que a escola não é o único alvo dos grupos extremistas que organizam e financiam essas ações, mas que isso parte de uma intencionalidade muito maior e talvez a principal: destituir a democracia, controlar indivíduos, destruir direitos sociais, políticos e humanos, instituindo o autoritarismo ditatorial mais uma vez no país (BIJEGA, 2019).

É nesse sentido que reivindicamos a necessidade de políticas de enfrentamento a essa lógica antidemocrática, sendo fundamental nesse processo uma articulação coletiva para implementar ações de proteção à nossa jovem democracia e à nossa educação, afinal, inúmeras são as situações onde os agentes educacionais expressam o seu temor diante das atuais circunstâncias que flertam com "a volta de um governo militar, a queda da democracia"xiv e outras formas de ataque à descentralização, à participação e à autonomia, como afirma uma profissional que atua na área da educação especial há mais de vinte anosem sua participação em nossa pesquisa online. Esta mesma profissional ressalta um elemento que a gestão autoritária (e excludente) da educação brasileira desconsidera sobremaneira: o direito às aulas presenciais e o despreparo dos pais para o acompanhamento em atividades 
educacionais remotas. Cabe ressaltar que esta foi a preocupação que justificou a discussão apresentada na seção a seguir.

\section{Educação em tempos de pandemia: autoritarismo, precarização e exclusão em evidência}

Trabalho com alunos com deficiência visual e com deficiência múltipla. Tenho encaminhado atividades semanalmente para os familiares que quiserem e puderem fazer, mas apenas como sugestão, deixando claro que seus filhos têm direito a aula presencial, com interação direta entre professores e alunos, metodologias e recursos especializados, profissionais da educação formados para isso. A tecnologia é ótima, mas tem seus limites. Acima de tudo, é preciso considerar que os pais, mesmo quando têm nível superior, não são formados para atuar no aprendizado referente à educação formal. No meu caso, alguns pais sabem ler, mas não entendem as proposições das atividades e não têm conhecimento para intervir nas respostas dos alunos, que normalmente são diversas do esperado padrão. ${ }^{x v}$

A fala que trazemos na epígrafe acima expõe a sensível preocupação de uma professora com a realidade de muitas famílias brasileiras que, nesse momento difícil pelo qual estamos passando, têm que se reinventar para dar conta das dificuldades financeiras, familiares, profissionais e emocionais causadas pela pandemia da Covid-19. Insfran e Muniz (2020) entendem que

a dura realidade que se impõe a todos/as com o isolamento social/ físico única medida segura de controle da pandemia encontrada até agora - além de gerar uma grave crise econômica no mundo todo, tem causado sobrecarga na saúde mental de grande parte da população mundial, sobretudo nas mulheres [...] [pois] [...] machismo, sexismo, conservadorismo e capitalismo tendem a sacrificar mais as mulheres do que os homens, devido a imposição de papéis sociais que atribuem longas e exaustivas jornadas de trabalho reprodutivo às mulheres concomitantemente ao trabalho produtivo (pior remunerado que o dos homens) realizado (INSFRAN, MUNIZ, 2020, p.35-37).

Assim, nestes tempos de pandemia, muitas desigualdades têm saltado aos olhos até de pessoas menos sensíveis e empáticas às dores daqueles muito distintos de si e das suas referências. Especificamente falando do campo da educação, temos vivido desde o início do isolamento dilemas e conflitos com relação ao modelo de ensino imposto, que trouxe para a realidade de milhões de pessoas, da noite para o dia, ferramentas tecnológicas com as quais grande parte da população tem pouca ou nenhuma familiaridade. Tanto professoras/es (que se tornaram youtubers em aulas ao vivo e/ou gravadas) como alunos/as e suas famílias têm feito queixosos relatos de dificuldades nesta modalidade de ensino remoto (SCHNEIDER, 2020) que até poderíamos chamar de Educação à Distância $(\mathrm{EaD})$ não fosse a precariedade do ineditismo excludente dessa modalidade emergencial de educação. ${ }^{\text {xvi }}$ 
Percebemos que, mais uma vez, um modelo novo e desconhecido é introduzido na educação sem diálogo com o "chão de escola", sem preocupação ou respeito às condições sociais, materiais, tecnológicas, logísticas, emocionais e físicas de professores, alunos e famílias. Entendemos que a tomada de decisões de cima para baixo é uma ação diametralmente oposta às práticas democráticas. A democracia deve ser construída a partir do esforço de muitas mãos e mentes, para que haja o respeito à vontade e aos anseios de uma maioria, levando sempre em consideração os impactos dessas decisões sobre a imensa massa de vidas que compõem o todo da sociedade.

Portanto, o ensino remoto emergencial, ainda que em contexto de democracia, tem anulado os princípios da isonomia e da isegoria constitucionalmente garantidos a todos (BRASIL, 1988), pois fazem parte deste processo de educação apenas aqueles que tiverem acesso a no mínimo um computador ou um celular, com acesso à internet de banda larga que possa reproduzir vídeos. Professores também precisam ter disponível estas tecnologias, além de espaço de armazenamento (físico e/ou virtual) para fazer, reproduzir e salvar suas vídeo aulas. Também precisam dispor de conhecimento tecnológico (sem treinamento e capacitação fornecido anteriormente) suficiente para acessar e utilizar as plataformas de educação remota compradas pelas secretarias de educação, escolas e universidades públicas e/ou privadas.

Dados da pesquisa TIC Domicílios 2019, do Centro Regional de Estudos para o Desenvolvimento da Sociedade da Informação (CETIC, 2020), mostrou que apenas 37\% dos domicílios brasileiros possuíam computador e internet em 2019. Entre as famílias pertencentes às classes sociais $\mathrm{D}$ e $\mathrm{E}$, somente $12 \%$ possuíam essas duas tecnologias e $85 \%$ acessavam a internet apenas pelo celular.

Esses dados em conjunto com outros que expõem as precárias condições de existência de uma grande parcela da população - $16 \%$ da população $(31,1$ milhões de brasileiros) não têm acesso a água encanada e $37 \%$ da população (74,2 milhões de pessoas) vivem sem saneamento básico, segundo dados da PNAD/IBGE apresentados no portal G1 (SILVEIRA, 2020) - apontam para as impossibilidades de modelo remoto de educação.

Tanto em áreas urbanas como rurais, muito jovens relatam desesperança no futuro, segundo a pesquisa "Juventudes e a pandemia do coronavírus" (CONJUVE, 2020; GRANDELLE, 2020). Três em cada dez jovens relataram vontade de abandonar os estudos após a pandemia e metade dos mais de 30 mil entrevistados relataram pensar em desistir do ENEM (67\% disseram não terem conseguido estudar para a prova desde que as aulas presenciais foram suspensas). Percebemos que dentre as dificuldades trazidas pela pandemia que os jovens de 15 a 29 anos entrevistados apontaram, as questões relacionadas à educação 
se sobressaem, já que muitos relatam inadaptação ao ensino remoto e sentirem falta da relação com professores e colegas. O distanciamento/ perda do vínculo com a escola, assim como da rede de proteção que ela gera (OLIVEIRA, PAIVA, RIZZINI, 2020), é um fator preponderante na decisão dos estudantes em evadir (GRANDELLE, 2020). Muñoz (2020) traz relatos preocupantes de experiências educacionais internacionais durante a pandemia da Covid-19, conforme vemos a seguir:

O fechamento das escolas pode significar a interrupção do processo de aprendizagem principalmente para crianças com alta vulnerabilidade. A ausência de interação entre estudantes e professores rompe o processo de aprendizagem e se a pandemia durar muitas semanas, não será possível recuperar o tempo perdido quando as escolas reabrirem. Também se eleva o risco de aumentar as taxas de abandono escolar, especialmente entre os alunos de famílias em situação de alta vulnerabilidade (MUÑOZ, 2020).

Dessa forma, entendemos que pensar o modo como a educação se construiu ao longo da Históriaé pensar que ela esteve sempre relacionada ao contato social, à troca de experiências, através da socialização no âmbito primário, mesmo que silenciosa, ou de modo secundário através das narrativas míticas transmitidas pelos poetas na antiguidade clássica, que continham sempre um teor moralizante e educativo por excelência. Tutores e professores, na maioria das circunstâncias, sempre foram ocupações de pessoas pertencentes à comunidade, de conhecimento das famílias; muitas vezes do círculo de relações sociais. Desse modo, assegurou-se que a interação pudesse cumprir um papel importante (FERREIRA, 1994; JOAS, 1999).

A necessidade de trabalhar para suprir a queda de renda familiar também é um fator que surge como dificuldade para os jovens estudantes (GRANDELLE, 2020). Enquanto isso, ao Estado "resta" apenas a oferta das habituais ações assistencialistas que mantém a população refém de uma lógica que aniquila sua possibilidade de romper com o ciclo da coisificação tão claramente expresso pelo fetichismo mercadológico. Assistimos, assim, uma educação conduzida por políticas projetadas em um grande hiato das reais necessidades e carências de nosso povo. Uma educação despreocupada e desconectada das subjetividades envolvidas na ponta desse processo, ou seja, no "chão da escola".

Nossas escolas e nossa educação carregam em sua trajetória marcas profundas de autoritarismo e exclusão. Seus interesses e diretrizes reproduzem manifestamente as vontades e projetos político-econômicos de nossas classes dominantes, em detrimento dos interesses reais e necessários às massas exploradas (PATTO, 2009). Assim, vemos um cenário onde a educação mais do que nunca se torna uma ideologia de posse e representação classista, visto que tenta promover controle das práticas docentes monitoradas em tempo real (pelas 
plataformas educacionais), de modo a evitar a suposta doutrinação ideológica, ao mesmo tempo em que é desprovida de qualquer interesse na garantia do direito de aprender (RAMOS, 2019).

Portanto, as investidas contra a educação crítica, reflexiva e emancipadora (FERNANDES, 2013) e a tentativa de controle/ punição daqueles que resistem em reafirmar direitos universais de acesso a uma educação libertadora - honrando dessa forma a memória do patrono da educação brasileira, o atualmente perseguido Paulo Freire (1987) - encontram neste dramático momento de crise que vivemosa oportunidade de ouro de implementar definitivamente uma educação pública a serviço do mercado e dos empresários da educação. Cabe a nós, defensores da manutenção e expansão desses direitos insistir, entre diversos setores e indivíduos, na importância de que essas garantias universais (como saúde e educação) sejam oferecidas com qualidade pelo poder público (GOMES, 2020), durante e também depois da crise sanitária que estamos atravessando.

\section{Considerações finais: qual o lugar do professor na democracia participativa?}

Epígrafe: as palavras que são gravadas no pedestal de uma estátua, placa, lápide, medalha etc. [Literatura] Citação que se coloca no princípio de um livro (poema, conto, capitulo etc.), servindo de resumo para o assunto que será abordado e, além disso, apresentando o sentido e a motivação da obra; mote $^{\text {xvii }}$

Subvertendo normas, falas de anônimas/os no lugar de clássicos. Epígrafes são geralmente usadas para gravar/ inscrever/ homenagear grandes clássicos que nos inspiraram na escrita e na visão de mundo. As/os educadoras/es brasileiras/os nos inspiram! E é por isso que as epígrafes deste artigo foram o espaço destinado para estas/es profissionais aliviarem suas dores e angústias, denunciarem a falsa democracia que muitos insistem em legitimar e naturalizar, "passando pano" para opressões, desmandos, assédios e toda a impossibilidade imposta ao fazer pedagógico diário e sofrido dessas/es anônimas/os educadoras/es.

Chegando a este ponto de nossa discussão, percebemos que reconstruímos um espaço que há muito é ocupado por diferentes indivíduos que não possuem o mesmo preparo, e, por isso, colaboraram para rebaixar a importância do processo educacional e da figura do professor. Mas ainda assim, o professor continua na linha de frente, sobretudocom o mesmo ânimo por seu trabalho, que convertido em arte torna-se ainda mais indispensável para qualquer realidade que se deseje modificar, principalmente dentro de um contexto de democracia. 
Vimos em nossa pesquisa online, que lembramos, ainda está em análise, inúmeros professores de todos os segmentos da Educação Básica e do Ensino Superior exporem seus temores sobre o futuro da educação no pós-pandemia, bem como as dificuldades enfrentadas no exercício de sua profissão. Falas suficientes para justificar o desejo de seguir outros caminhos, na intenção de encontrar a valorização que outras áreas menos estratégicas para uma nação encontram com maior facilidade, mas que ao professorparece impossível.

Contudo, o que nos motivou a seguir com o estudo dos resultados da pesquisa, e que também nos trouxe para esta discussão, aqui, neste artigo, foi perceber que para estes profissionaisnão há nada mais importante na vida do que o ato de ensinar, construir um legado e contribuir para que a realidade não seja forjada segundo interesses escusos e mercadológicos, mas que seja aquela que de fato represente os anseios de toda a coletividade, que de olhos abertosserá capaz de perceber o que a constrói e sustenta.

Não temos a intenção de sacralizar a imagem do professor, tocando em ideias como a do amor pela profissão, ou vocação, pois assim não seria possível identificar o grau de humanidade contido na alma de um professor. Mas queremos ofertar a eleo espaço que é seu por direito, com a consequente importância e destaque que lhe cabe. Por isso, ele está sob o foco, para evidenciar que seu trabalho é pura resistência diante de uma democracia ainda em busca de plena força frente ao autoritarismo amplamente reforçado em tempos de crise.

E essa democracia, muitas vezes forjada em decisões unilaterais tomadas de cima para baixo - levando em consideração os interesses econômicos das classes dominantes -, está sob ameaça. Sabemos que o contexto histórico da educação brasileira tem muitos tipos, caminhos e protagonismos. Mas esse momento em que localizamos as incertezas nessa pandemia também coloca sob holofotes as muitas incoerências e desdobramentos de uma política educacional que está interessada em promover uma estrutura meritocrática, competitiva e de capital humano descartável.

Porém, expor as contradições de nossa frágil e burocratizada democracianão nos faz querer prescindir dela. Não nos interessa dispor ou abrir mão da democracia - que ainda temos - porque não deu certo ou não é de fato representativa e participativa, como pensam/ sentem aqueles que embarcam nos movimentos antidemocráticos e protofascistas. Cabe a nós fortalecê-la, via coletividades, resistindo aos sucessivos ataques e tentativas de desmonte dos nossos espaços colegiados de debate e construção de caminhos que passem ao largo dos interesses meramente econômicos. Dessa forma, faz sentido para nós a crítica que Florestan Fernandes (1980) faz à democracia burguesa, explicitando a difícil conciliação entre os interesses das elites e da classe trabalhadora: 
Não foi um erro confiar na democracia e lutar pela revolução nacional. $\mathrm{O}$ erro foi outro - o de supor que se poderiam atingir esses fins percorrendo a estrada real dos privilégios na companhia dos privilegiados. Não há reforma que concilie uma minoria prepotente a uma maioria desvalida (FERNANDES, 1980, p.245-246).

Em suma, fica claro para nós que essa é uma discussão inesgotável cujos reflexos são imensos, reverberando em perda da qualidade da educação ao passo em que precariza em ritmo desenfreado o trabalho docente, promovendo processos de adoecimentos e autoculpabilização. Diante desse cenário de colapso da democracia participativa, nos cabe pensar qual escola encontraremos pós pandemia, pois as ausências neste momento atual trazem à tona um caminho cheio de suor e ansiedade. Percebemos, assim, como esse cenário contribui ainda mais para minar a luta por uma escola pública democrática e para promover sentimentos de culpa/ insuficiência/ frustração nos profissionais de educação. O Estado se propõe pensar/ investir na educação, porém convenientemente sustenta políticas públicas que anulam subjetividades docentes e discentes e os condiciona à lógica do mercado (GOMES, 2020).

E a nós, o que interessa? Nos interessa a vida! E para isso, resistir é preciso. O isolamento não silenciou nossas vozes. Seguimos ecoando as vozes das/os colegas professoras/es nas denúncias contra a opressão cotidiana e lutando coletivamente contra o desmonte da educação pública, gratuita, de qualidade, socialmente referenciada a qual tivemos o privilégio de ter acesso (e que queremos como direito universal de todos/todas e não como privilégio de poucos). Seguimos, assim, esperançando a construção de uma sociedade na qual o lucro não se sobreponha à vida.

\section{Referências}

ABRUCIO, F. L.; LOUREIRO, M. R. Burocracia e ordem democrática: desafios contemporâneos e experiência brasileira In: PIRES, R.; LOTTA, G.; OLIVEIRA, V. E. (Orgs.). Burocracia e políticas públicas no Brasil: interseções analíticas. Brasília: IPEA, Enap, 2018, p. 23-57.

ASBAHR, F. S. F. Sobre o Projeto Político-Pedagógico: (im)possibilidades de construção. In: VIÉGAS, L. S.; ANGELUCCI, C. B. (Orgs.). Políticas Públicas em Educação.Uma análise Crítica a partir da Psicologia Escolar. 2.ed. São Paulo: Casa do Psicólogo, 2011. p. 229-243.

BIJEGA, G. L. Cidadania no Brasil: a nossa jovem democracia em risco. Foz do Iguaçu: Espirales, ed. especial, p. 1-13, 2019. 
BOULOS, G. A onda conservadora. DEMIER F., HOEVELER R., (Orgs.). A Onda Conservadora: ensaios sobre os atuais tempos sombrios no Brasil. 1. ed. Rio de Janeiro: Mauad; 2016. p. 29 - 32.

BRASIL. [Constituição (1988)]. Constituição da República Federativa do Brasil de 1988. Brasília, DF: Presidência da República, [2020]. Disponível em: https://www.planalto.gov.br/ccivil_03/constituicao/constituicao.htm. Acesso em: 03 jul. 2020. BRASIL. Lei $\mathrm{n}^{\circ}$ 9.394, 20 de dezembro de 1996. Estabelece as diretrizes e bases da educação nacional.Brasília - DF: Presidência da República, [2009]. Disponível em: http://www.planalto.gov.br/ccivil_03/leis/19394.htm. Acesso em: 03 jul. 2020.

BRASIL. Parâmetros curriculares nacionais: introdução aos parâmetros curriculares nacionais. Brasília, DF: Ministério da Educação e do Desporto, Secretaria de Educação Fundamental, 1997. Disponível em: http://portal.mec.gov.br/seb/arquivos/pdf/livro01.pdf. Acesso em: 03 jul. 2020.

BRASIL. Política Nacional de Educação Especial na Perspectiva da Educação Inclusiva. Portaria nº555/2007, prorrogada pela Portaria nº 948/2007. Brasília, DF: Ministério da Educação e do Desporto, 2008. Disponível em: http://portal.mec.gov.br/arquivos/pdf/politicaeducespecial.pdf. Acesso em: 03 jul. 2020.

BRASIL. Base Nacional Comum Curricular. Brasília, DF: Ministério da Educação e do Desporto, 2017. Disponível em: http://portal.mec.gov.br/conselho-nacional-deeducacao/base-nacional-comum-curricular-bncc. Acesso em: 03 jul. 2020.

CASTRO, G. A. Mais duas cidades aprovam lei da escola sem partido. Curitiba: Gazeta do Povo, nov. 2017. Disponível em: https://www.gazetadopovo.com.br/educacao/mais-duascidades-aprovam-lei-da-escola-sem-partido-4wz257b4i37yzgjh3juletc9w/. Acesso em: 01 jul. 2020.

CETIC. Acesso a Tecnologias da Informação e da Comunicação (TIC) - Domicílios 2019. Cetic, São Paulo, 26 maio. 2020. Disponível em: https://www.cetic.br/pt/pesquisa/domicilios/indicadores/. Acesso em: 04 jul. 2020.

CFP. Conselho Federal de Psicologia. Referências técnicas para atuação de psicólogas(os) na educação básica. 2. ed. Brasília : CFP, 2019.

CIRNE, M. Professora da UCPel explica diferença entre EAD e atividade remota. Universidade Católica de Pelotas, Pelotas, 30 abr. 2020. Disponível em: https://www.ucpel.edu.br/noticias/professora-da-ucpel-explica-diferenca-entre-ead-eatividade-remota. Acesso em: 04 jul. 2020.

CONJUVE. Pesquisa Juventudes e a pandemia do coronavírus. Conselho Nacional de Juventude. 2020. Disponível em: https://www.juventudeseapandemia.com. Acesso em: 4 jul. 2020.

DEMIER F. O barulho dos inocentes: a revolta dos "homens de bem". In: DEMIER F., HOEVELER R., (Orgs.). A Onda Conservadora: ensaios sobre os atuais tempos sombrios no Brasil. 1. ed. Rio de Janeiro: Mauad; 2016. p. 9-24. 
FELICIO, S.C. Subjetividades docentes e a expansão do judiciável: a "escola sem partido" e o adoecimento de professores. Tese (doutorado acadêmico). Universidade Federal Fluminense. Programa de Pós-graduação em Psicologia, 2019.

FERNANDES, F. A Revolução Burguesa no Brasil. Ensaio de Interpretação Sociológica. 2. ed. Rio de Janeiro: Zahar Editores, 1976.

FERNANDES, F. A sociologia no Brasil. Petrópolis: Vozes, 1980.

FERNANDES, F. Mudanças sociais no Brasil: aspectos do desenvolvimento da sociedade brasileira. 1. ed. Dig. São Paulo: Global Editora, 2013.

FERREIRA, R. M. Sociologia da Educação. São Paulo: Moderna, 1994.

FREIRE, P. Pedagogia do Oprimido. 17. ed. Rio de Janeiro: Paz e Terra, 1987.

FRIGOTTO, G. A gênese das teses do Escola sem Partido: esfinge e ovo da serpente que ameaçam a sociedade e a educação. In: FRIGOTTO, G. (Org.). Escola "sem" partido: esfinge que ameaça a educação e a sociedade brasileira. 2. ed. Rio de Janeiro: UERJ, 2019. p. 19-36.

GOMES, R.L.R. Aspectos da educação brasileira em meio aos dilemas de um momento dramático. In: LOLE, A.; STAMPA, I.; GOMES, R.L.R. (Orgs.). Para além da quarentena: reflexões sobre crise e pandemia. E-book. Mórula Editorial; 2020.

GRANDELLE, R. Três em cada dez jovens pensam em largar a escola após pandemia do coronavírus. Jornal O Globo, Rio de Janeiro, 22 jun. 2020. Disponível em: https://oglobo.globo.com/sociedade/tres-em-cada-dez-jovens-pensam-em-largar-escola-apospandemia-do-coronavirus-diz-pesquisa-1-24493252. Acesso em 4 jul 2020.

INSFRAN, F. F. N. A formação de professores num contexto neoliberal: como resistir? In: LEMOS, F. C. S. et al (Orgs.). Conversas transversalizantes entre psicologia politica, socialcomunitária e institucional com os campos da educação, saúde e direitos. v. 7, 1. ed. Curitiba: CRV, 2017. p.191-198.

INSFRAN, F. F. N.; MUNIZ, A. G. C. R.; ARAUJO, G. G. Problemas de escolarização, medicalização e docência: outros olhares. Práxis Educacional, [s.1.], v. 15, n. 36, p. 84-107, dez. 2019.

INSFRAN, F. F. N.; MUNIZ, A. G. C. R. Maternagem e Covid-19: desigualdade de gênero sendo reafirmada na pandemia. Diversitates. Dossiê especial: COVID-19 e Desafios Contemporâneos da Saúde Coletiva e Bioética. v.12, n.2, p.26-47, 2020.

JOAS, H. Interacionismo Simbólico. In: GIDDENS, A.; TURNER, J. (Orgs.). Teoria Social Hoje. São Paulo: Editora UNESP, 1999.

LEAL, B. Pedagoga explica diferença entre ensino remoto e EAD. Centro Universitário Maurício de Nassau, Maceió, 20 maio. 2020. Disponível em: https://www.uninassau.edu.br/noticias/pedagoga-explica-diferenca-entre-ensino-remoto-e-ea. Acesso em: 04 jul. 2020. 
LINARES, A.; BEZERRA, J.E.B. Obscurantismo contra a liberdade de ensinar. In: CASSIO, F. (Org.). Educação contra a barbárie: por escolas democráticas e pela liberdade de ensinar. 1. ed. São Paulo: Boitempo, 2019. p.127-133.

MARKOFF, J. Democracia: transformações passadas, desafios presentes e perspectivas futuras. Porto Alegre: Revista Sociologias, a. 15, n. 32, p.18-50. jan/abr 2013.

MONTESQUIEU, C. Do Espírito das Leis - Livro 1: Leis e Costumes. MELVILLE, J. (Trad.). Coleção a Obra Prima de Cada Autor. São Paulo: Martins Claret, 2007.

MUÑOZ, R. A experiência internacional com os impactos da COVID-19 na educação. Nações Unidas Brasil. 08 abr. 2020. Disponível em: https://nacoesunidas.org/artigo-aexperiencia-internacional-com-os-impactos-da-covid-19-na-educacao/. Acesso em: 04 jul. 2020 .

NOBRE, N. Sem consenso, projeto sobre Escola sem Partido será arquivado. Agência Cãmara de Notícias. Câmara dos Deputados, Brasília, 11 dez. 2018. Disponível em: https://www.camara.leg.br/noticias/549616-sem-consenso-projeto-sobre-escola-sem-partidosera-arquivado/. Acesso em: 04 jul. 2020.

NOGUEIRA, F. M. G. (Org.). Estado e políticas sociais no Brasil. Cascavel: Edunioeste, 2006.

OLIVEIRA, A.C.;PAIVA, A.R.; RIZZINI, I. As/os assistentes sociais na linha de frente: violência e violações de direitos na pandemia da COVID-19. In: LOLE, A.; STAMPA, I.; GOMES, R.L.R. (Orgs.). Para além da quarentena: reflexões sobre crise e pandemia. Ebook. Mórula Editorial; 2020.

PATTO, M. H. S. A cidadania negada: políticas públicas e formas de viver. São Paulo: Casa do Psicólogo, 2009.

PATTO, M. H. S. A Produção do Fracasso Escolar: histórias de submissão e rebeldia. 4. ed., revista e ampliada. São Paulo: Intermeios, 2015.

PENNA, F. A. O Escola sem Partido como chave de leitura do fenômeno educacional. In: FRIGOTTO, G. (Org.). Escola "sem" partido: esfinge que ameaça a educação e a sociedade brasileira. 2. ed. Rio de Janeiro: UERJ, 2019. p. 35-48.

PESSANHA, J. A. M.; SOUZA, J. C.; PALEIKAT, J.; COSTA, J. C. Os Pensadores: Platão. $5^{\text {a }}$ ed. São Paulo: Nova Cultural, 1991.

PICARELLI, M. Militarização das escolas públicas: soldado ou cidadão?. São Paulo: Revista Educação, ed. 257, abr., 2019. Disponível em:

https://revistaeducacao.com.br/2019/04/29/militarizacao-das-escolas/. Acesso em: 03 jul. 2020.

RAMOS, M.N. Escola sem Partido: a criminalização do trabalho pedagógico. In:

FRIGOTTO, G. (Org.). Escola "sem” partido: esfinge que ameaça a educação e a sociedade brasileira. 2. ed. Rio de Janeiro: UERJ, 2019. p. 77-87. 
SALDAÑA P.; CARAZZAI E. H.; GAMBA E.; TAKAHASHI F. Escolas militares e colégios civis com mesmo perfil têm desempenho similar. Folha de São Paulo, São Paulo, fev. 2019. Disponível em: https://www1.folha.uol.com.br/educacao/2019/02/escolasmilitares-e-colegios-civis-com-mesmo-perfil-tem-desempenho-similar.shtml. Acesso em: 01 jul. 2020.

SCHNEIDER, A. O pesadelo do ensino remoto. Folha de São Paulo, São Paulo, 02 jul. 2020. Disponível em: https://www1.folha.uol.com.br/colunas/alexandre-schneider/2020/07/opesadelo-do-ensino-remoto.shtml. Acesso em: 04 jul. 2020.

SILVEIRA, D. Coronavírus e desafios à prevenção: Brasil tem 31,3 milhões sem água encanada e 11,6 milhões em casas 'superlotadas'. G1, Rio de Janeiro, 28 mar. 2020. Disponível em: https://g1.globo.com/economia/noticia/2020/03/28/coronavirus-e-desafios-aprevencao-brasil-tem-313-milhoes-sem-agua-encanada-e-116-milhoes-em-casassuperlotadas.ghtml. Acesso em: 04 jul. 2020.

SOUZA, H.J. Como se faz análise de conjuntura. 34ª ed. Petrópolis: Vozes, 2016.

SOUZA, M.P.R. Políticas Públicas e Educação: desafios, dilemas e possibilidades. In: VIÉGAS, L. S.; ANGELUCCI, C. B. (Orgs.). Políticas Públicas em Educação. Uma análise Crítica a partir da Psicologia Escolar. 2. ed. São Paulo: Casa do Psicólogo, 2011, p. 229-243.

TEÓFILO, S. Apuração de protestos anti democráticos deve ganhar mais força. Brasília, DF: Correio Braziliense, jun. 2020. Disponível em:

https://www.correiobraziliense.com.br/app/noticia/politica/2020/06/28/interna politica,86747 8/apuracao-de-protestos-antidemocraticos-deve-ganhar-mais-forca.shtml. Acesso em: 01 jul. 2020.

TOCQUEVILLE, A. A Democracia na América. BRANDÃO, E. (trad.). São Paulo: Martins Fontes, 2005.

WEFFORT, F. C. (Org). Os clássicos da política. São Paulo: Ática, 1998.

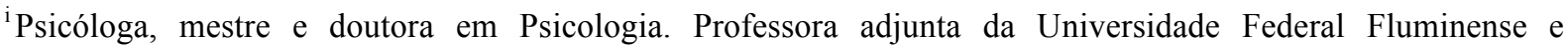
credenciada ao Programa de Pós Graduação em Ensino (PPGEn/UFF). Líder do Núcleo de Estudos Interseccionais em Psicologia e Educação (NEIPE/UFF). E-mail: fernanda_insfran@id.uff.br . ORCID http://orcid.org/0000-0002-5097-1599

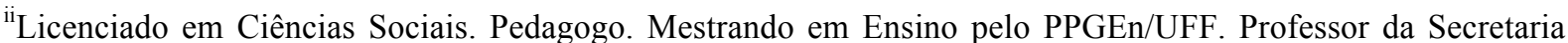
Estadual de Educação - SEEDUC/RJ. Membro do Núcleo de Estudos Interseccionais em Psicologia e EducaçãoNEIPE/UFF. E-mail: paulo.43474071@,educa.rj.gov.br. ORCID_https://orcid.org/0000-0002-4780-4351

iii Pedagoga. Mestranda em Ensino pelo PPGEn/UFF. Membra do Núcleo de Estudos Interseccionais em Psicologia e Educação - NEIPE/UFF. E-mail:estefanysamela@gmail.com .ORCID https://orcid.org/0000-00017927-3666

${ }^{\text {iv }}$ Pedagogo. Mestre em Ensino pelo PPGEn/UFF. Professor do primeiro segmento do ensino fundamental no município de Bom Jesus do Itabapoana/RJ. Membro do Núcleo de Estudos Interseccionais em Psicologia e Educação - NEIPE/UFF, membro do Núcleo de Pesquisa em Trabalho e Educação - NUPETE/UFF. E-mail: thalles-ladeira@hotmail.com . ORCID https://orcid.org/0000-0003-1873-9113
} 
${ }^{v}$ Graduado em História. Mestrando em Ensino pelo PPGEn-INFES-UFF. Professor da SEEDUC-RJ. Membro do Núcleo de Estudos Interseccionais em Psicologia e Educação - NEIPE/UFF. E-mail: sentinelli83@gmail.com . ORCID https://orcid.org/0000-0002-7237-7128

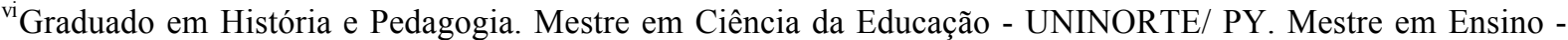
INFES/UFF. Professor da Educação básica SMEC - Santo Antônio de Pádua. Membro do núcleo de Estudos Interseccionais em Psicologia e Educação - NEIPE/UFF. E-mail: waldyr_barcellos@hotmail.com . ORCID https://orcid.org/0000-0002-7185-3874

\footnotetext{
vii Professor branco, entre 41 e 50 anos, pós-graduado, leciona na educação básica pública e tem renda familiar entre 3 e 6 salários mínimos, participante da pesquisa ainda em análise realizada pelo Núcleo de Estudos Interseccionais em Psicologia e Educação - NEIPE/UFF.

viii Professora negra ou parda, entre 31 e 40 anos, graduada, leciona na educação básica pública e tem renda familiar entre 3 e 6 salários mínimos, participante da pesquisa ainda em análise realizada pelo Núcleo de Estudos Interseccionais em Psicologia e Educação - NEIPE/UFF.

${ }^{\mathrm{ix}}$ Professora branca entre 51 e 60 anos, pós graduada, leciona no ensino médio público e tem renda familiar entre 3 e 6 salários mínimos, participante da pesquisa ainda em análise realizada pelo Núcleo de Estudos Interseccionais em Psicologia e Educação - NEIPE/UFF.
}

${ }^{x}$ Nome dado ao método utilizado por Sócrates para construir conhecimento e que se utiliza também da ironia, que suscita a reflexão e leva o indivíduo a elaborar pensamentos. A expressão representa o ato de "dar a luz" às ideias, pois Sócrates acreditava que o conhecimento está dentro de nós aguardando uma experiência que o traga à tona (PESSANHA, 1991).

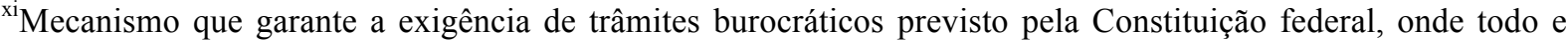
qualquer projeto de lei ou ação governamental deva ser submetido à apreciação pelo poderes legislativo e executivo, objetivando tornar clara a estrutura das propostas e ações, não só aos congressistas, mas também à imprensa e sobretudo à população; para que todos se manifestem e, para que seja garantido o princípio da democracia (MONTESQUIEU, 2007; TOCQUEVILLE, 2005).
\end{abstract}

\begin{abstract}
${ }^{\text {xii }}$ Pesquisador autônomo, branco, entre 31 e 40 anos, pós-graduado, com renda entre 1 e 3 salários mínimos, que recorreu à docência no Ensino Médio público do estado de São Paulo, como forma de complementar sua renda há três anos, que denuncia precarização do trabalho. Participante da pesquisa ainda em análise realizada pelo Núcleo de Estudos Interseccionais em Psicologia e Educação - NEIPE/UFF.
\end{abstract}

xiii Professor com título de doutorado, branco, com idade entre 31 e 40 anos, que leciona no Ensino Médio e Superior público, com renda superior a 10 salários mínimos, conforme aponta pesquisa ainda em análise realizada pelo Núcleo de Estudos Interseccionais em Psicologia e Educação - NEIPE/UFF.

${ }^{\text {xiv }}$ Professora negra ou parda, com idade entre 41 e 50 anos. Atua na rede estadual de educação do Rio de Janeiro; dividindo-se entre o Ensino Regular e a Educação Especial, fator que evidencia ainda mais a diferença dentro do próprio sistema educacional e expõe as demonstrações de exercício de poder, conforme aponta pesquisa ainda em análise realizada pelo Núcleo de Estudos Interseccionais em Psicologia e Educação - NEIPE/UFF.

\footnotetext{
${ }^{\mathrm{xv}}$ Idem nota acima.

${ }^{x v i}$ Profissionais que trabalham com EaD foram os primeiros a apontar diversas distinções entre ensino remoto emergencial e educação à distância, conforme vimos em diversas lives e algumas entrevistas (LEAL, 2020; CIRNE, 2020), ao longo dos últimos meses. Talvez por preverem o fracasso do primeiro, apostaram no descolamento dos termos como forma de resguardar os méritos (e ganhos) da EaD.
}

xvii Definição retirada do dicionário online de Português. Disponível em:https://www.dicio.com.br/epigrafe/ Acesso em 4 jul 2020. 